\title{
PERSPEKTIF MAHASISWA FAKULTAS PSIKOLOGI ANGKATAN 2015 \\ UNIVERSITAS YARSI JAKARTA PUSAT TERHADAP APLIKASI Chemical Castration (KEBIRI )BAGI PELAKU KEKERASAN SEKSUAL ANAK DI INDONESIA DAN TINJAUANNYA MENURUT ISLAM
}

\author{
Nisrina Nurul Insani ${ }^{1}$, Bambang Poerwantoro ${ }^{2,}$ Zuhroni $^{3}$ \\ ${ }^{1}$ Faculty of Medicine, YARSI University \\ ${ }^{2}$ Medikolegal Department Faculty of Medicine YARSI University \\ ${ }^{3}$ Islamic Department Faculty of Medicine, YARSI University \\ E-mail: nisrinanurul@ymail.com
}

\begin{abstract}
ABSTRAK
Tingkah laku kriminal kekerasan seksual memiliki tingkat kuantitas yang cukup tinggi di Indonesia, dan tak jarang yang menjadi korban dalam kasus kriminalitas jenis ini adalah anak yang usianya masih dibawah umur. pada Mei 2016, Presiden Joko Widodo telah menandatangani peraturan pemerintah pengganti undang-undang (Perppu) nomor 1 tahun 2016 perubahan kedua nomor 23 tahun 2002 mengenai perlindungan anak. Dalam perppu dijelaskan, pelaku tindak kejahatan seksual terhadap anak, dapat diancam dengan hukuman mati. Sementara, kebiri dengan menggunakan zat kimia dan pemasangan alat deteksi elektronik juga dapat menjadi pertimbangan hakim untuk memberikan hukuman tambahan. Penelitian ini bertujuan untuk mengetahui perspektif mahasiswa fakultas psikologi angkatan 2015 Universitas Yarsi Jakarta Pusat terhadap aplikasi chemical castration (kebiri) bagi pelaku kekerasan seksual anak di indonesia dan tinjauannya menurut Islam. Metode penelitian yang digunakan deskriptif dengan pendekatan cross sectional. Teknik pengambilan sampel dalam penelitian ini adalah purposive sampling. Hasil memperlihatkan bahwa dari 32 responden, terdapat 18 responden $(56,3 \%)$ yang tidak setuju dan 14 mahasiswa $(43,7 \%)$ yang setuju. Perspektif mahasiswa fakultas psikologi angkatan 2015 Universitas Yarsi Jakarta Pusat tidak setuju terhadap aplikasi chemical castration (kebiri) bagi pelaku kekerasan seksual anak di Indonesia. Menurut pandangan Islam, diberlakukannya kebiri kimia sebagai hukuman bagi pelaku kekerasan seksual hukumnya haram karena termasuk penyiksaan manusia dan merusak tubuh.
\end{abstract}

Kata kunci : kebiri kimia, chemical castration, kekerasan seksual, perspektif, psikologi

\section{ABSTRACT}

The criminal behavior of sexual violence has a fairly high level of quantity in Indonesia, and not infrequently victims of this type of crime are children of underage. in May 2016, President Joko Widodo has signed a law enforcement regulation (Perppu) number 1 of 2016 on the second change number 23 of 2002 on child protection. In the perppu described, perpetrators of sexual crimes against children, can be threatened with the death penalty. Meanwhile, the use of chemical substances and the installation of electronic detection equipment can also be considered by the judge to provide additional punishment. This study aims to determine the perspective of students faculty of psychology class of 2015 Yarsi University central Jakarta to the application of chemical castration (kebiri) for child sex offenders in Indonesia and its review according to Islam. Research method used descriptive with cross sectional approach. Sampling technique in this research is purposive sampling. The result showed 32 respondents, 18 respondents $(56.3 \%)$ did not agree and 14 students (43.7\%) agreed. Student perspective of the faculty of psychology class of 2015 Yarsi University Central Jakarta does not agree to the application of chemical castration (kebiri) for child sexual violence perpetrators in Indonesia. According to Islam's view, the enactment of chemical curiosity as punishment for perpetrators of sexual violence is forbidden because it includes human torture and bodily harm.

Keywords:castration, chemical castration, sexual violence, perspective, psychology 


\section{Pendahuluan}

Tingkah laku kriminal kekerasan seksual memiliki tingkat kuantitas yang cukup tinggi di Indonesia, dan tak jarang yang menjadi korban dalam kasus kriminalitas jenis ini adalah anak yang usianya masih dibawah umur. Bentuk pelecehan seksual pada anak termasuk meminta atau menekan seorang anak untuk melakukan aktivitas seksual, memberikan paparan yang tidak selayaknya untuk ditampilkan pada anak. ${ }^{1}$ Berdasarkan pemantauan yang dilakukan oleh Kementerian Koordinator bidang Pembangunan Manusia dan Kebudayaan (Kemenko PMK), tindak kekerasan terhadap anak sejak bulan Januari hingga April tahun 2017 berjumlah sebanyak 408 kasus. 306 kasus di antaranya merupakan kasus kekerasan seksual terhadap anak. Sementara berdasarkan data dari Komisi Perlindungan Anak Indonesia (KPAI), puncak tindak kekerasan terhadap anak terjadi pada tahun 2014 dengan jumlah mencapai 5.066 kasus. Jumlah ini meningkat sebanyak 755 kasus dibandingkan pada tahun 2013. Jumlah itu menurun pada tahun 2015 menjadi 4.309 kasus, namun meningkat lagi pada tahun $2016 \quad$ menjadi $4.482 \quad$ kasus (kemenkopmk.go.id). Pada Mei 2016, Presiden Joko Widodo telah menandatangani peraturan pemerintah pengganti undang-undang (Perppu) nomor 1 tahun 2016 perubahan kedua nomor 23 tahun 2002 mengenai perlindungan anak. Dalam perpu yang baru diteken itu, pelaku tindak kejahatan seksual terhadap anak, dapat diancam dengan hukuman mati. Sementara, kebiri dengan menggunakan zat kimia dan pemasangan alat deteksi elektronik juga dapat menjadi pertimbangan hakim untuk memberikan hukuman tambahan. ${ }^{2}$

Sejak awal, wacana pemberlakuan hukuman mati dan kebiri terhadap pelaku tindak kejahatan seksual sudah menuai pro dan kontra. Pakar seksologi dr. Boyke Dian Nugraha menilai hukuman kebiri bagi para pelaku kejahatan seksual kepada anak-anak tidaklah efektif. Alasannya, pelaku kejahatan seksual pada anak masih berpotensi melakukan aksi kejahatannya selama kondisi mentalnya tidak diobati. Psikolog anak, Seto Mulyadi meminta pemerintah untuk mengkaji ulang wacana memberikan hukuman kebiri bagi pelaku kejahatan seksual. Menurutnya secara psikologis, pelaku yang dikebiri ini dapat bertindak lebih agresif. Seto menyarankan bahwa anak-anak harus diberikan pendidikan seks sehingga mereka sendiri dari monster seksual. ${ }^{2}$ Kebiri kimia adalah tindakan memasukkan bahan kimiawi antiandrogen, baik melalui pil atau suntikan ke dalam tubuh pelaku tindak kejatahan 
seksual dengan tujuan untuk memperlemah hormon testosterone. ${ }^{3}$ Penggunaan obat hormonal untuk mengurangi tingkat kekerasan seksual pada residivisme (kecenderungan individu atau kelompok untuk mengulangi perbuatan tercela walaupun ia sudah pernah dihukum karena melakukan perbuatan itu) sebagai teknik kebiri secara kimia (chemical castration). ${ }^{4}$ Beberapa efek samping yang ditimbulkan dari pengibirian secara kimia terhadap pelaku kekerasan seksual jika dilihat dari sisi medis yaitu osteoporosis, penyakit kardiovaskular, gangguan metabolisme glukosa, lipid, depresi, infertilitas, dan anemia dapat juga terjadi. ${ }^{4}$ Pengebirian kimia juga dikaitkan dengan perubahan psikoneurologis termasuk peningkatan depresi dan kecemasan dan penurunan fungsi kognitif. Efek samping ini cenderung teratasi sendiri seiring dengan penghentian terapi kebiri, tapi harus dilakukan dengan serius. Hal yang lebih memperburuk perkembangan kelainan ini adalah kenyataan bahwa Banyak pelaku paraphiliac menderita gangguan psikologis yang sudah ada sebelumnya termasuk gangguan mood, depresi, gangguan bipolar, gangguan kecemasan, gangguan kontrol impuls, dan gangguan kepribadian avoidant. ${ }^{5}$ Mengingat masih adanya pro dan kontra dengan penerapan hukuman kebiri kimia maka penulis ingin mengetahui persepsi mahasiswa fakultas Psikologi angkatan 2015 Universitas YARSI Jakarta Pusat terhadap aplikasi hukum kebiri kimia (chemical castration) bagi pelaku kekerasan seksual pada anak di Indonesia dan tinjauannya menurut Islam.

\section{Metode Penelitian}

Penelitian ini bersifat deskriptif dengan pendekatan cross sectional. Populasi pada penelitian ini adalah 32 mahasiswa fakultas psikologi angkatan 2015 Universitas YARSI Jakarta Pusat. Teknik pengambilan sampel dalam penelitian ini adalah purposive sampling. Data yang dikumpulkan merupakan data primer yang berasal dari pengisian kuesioner oleh responden. Pengukuran data penelitian dengan cara menjumlahkan skor yang diperoleh dari jawaban responden dalam mengisi kuesioner yang diberikan dalam skala likert yang dikategorikan setuju dan tidak setuju. Dalam kuisioner, setiap pernyataan berisi dua pilihan dengan nilai berskala 0 dan 1 . Jawaban terendah diberi nilai 0 dan tertinggi diberi nilai 1 . Data yang diperoleh akan dimasukan ke komputer dan dianalisis menggunakan program Statistical Package for Social Science (SPSS) versi 22.0 for Windows. 
Hasil

Penelitian perspektif mahasiswa

fakultas psikologi angkatan 2015

universitas yarsi jakarta pusat terhadap aplikasi chemical castration (kebiri) bagi pelaku Kekerasan seksual anak di indonesiadengan menggunakan program Statistical Package for Social Science
(SPSS) versi 22.0 for Windows yang telah dilakukan terhadap 32 mahasiswa fakultas psikologi angkatan 2015 Universitas YARSI Jakarta Pusatdidapatkan kategori jumlah mahasiswa yang tidak setuju sebanyak 18 mahasiswa dengan persentase $56,3 \%$ dan setuju sebanyak 14 mahasiswa dengan persentase $43,7 \%$.

Tabel .1 Analisis Data

\begin{tabular}{ccc}
\hline Variabel & Frekuensi & Persentase (\%) \\
Tidak setuju & 18 & 56,3 \\
Setuju & 14 & 43,7 \\
\hline Total & 32 & 100,0 \\
\hline
\end{tabular}


Hasil penelitian ini menunjukan bahwa perspektif mahasiswa fakultas psikologi angkatan 2015 universitas yarsi jakarta pusat terhadap aplikasi chemical castration (kebiri) bagi pelaku kekerasan seksual anak di indonesia mayoritas tidak setuju dengan adanya perppu tersebut. Hal ini didukung oleh beberapa alasan yang di paparkan pada penelitian sebelumnya yaitu:

Pertama, hukuman kebiri tidak sesuai dengan tujuan pidana. Dalam ilmu hukum pidana, ada 3 teori yang menjelaskan tujuan dari hukum pidana, yakni pembalasan, memberikan efek jera, dan mengembalikan keadaan seperti semula. $^{6}$ Kedua, adanya upaya penghapusan hukuman kebiri di negara lain. Contohnya adalah Dewan Komite Eropa untuk Pencegahan Penyiksaan dan Hukuman yang Tidak Manusiawi dan Merendahkan Martabat Manusia (Council of Europe's Committee for the Prevention of Torture and Inhuman or Degrading Treatment or Punishment or CPT), sebuah komite pakar regional di Eropa yang bertugas melakukan pemantauan atas pelaksanaan konvensi, menentang penyiksaan serta memberikan berbagai rekomendasi atas berlakunya hukuman kebiri di negara yang tunduk pada pelaksanaan konvensi tersebut. Ketiga, ada efek samping dari hukuman kebiri. Kebiri kimiawi menimbulkan efek negatif berupa penuaan dini pada tubuh. Cairan anti- androgen diketahui akan mengurangi kepadatan tulang sehingga resiko tulang keropos atau osteoporosis meningkat. Antiandrogen juga mengurangi massa otot, yang memperbesar kesempatan tubuh menumpuk lemak dan kemudian meningkatkan resiko penyakit jantung jantung dan pembuluh darah. Hal ini tentunya tidak dapat dibenarkan karena seseorang akan dihukum melebihi atau tidak sebanding dengan apa yang ia perbuat.Di samping itu meskipun akan turun secara drastis dorongan seksualnya, akan tetapi masih ada faktor-faktor psikologis yang dapat menimbulkan kembali dorongan seksual. Pengebirian juga dapat menimbulkan kemungkinan pelaku menjadi lebih agresif karena faktor psikologis dan sosial, perasaan negatif, seperti sakit hati, marah, dan dendam dimana hal ini dimungkinkan terjadi sejak pelaku merasakan viktimisasi pada dirinya. ${ }^{7}$ Keempat, efek dari hukuman kebiri kimia bersifat sementara atau tidak bersifat permanen. Artinya, jika pemberian zat anti-androgen dihentikan, maka libido dan ereksinya dapat kembali lagi.Kelima, biaya untuk melaksanakan hukuman kebiri tidak murah.sekali suntik obat hanya mampu bekerja untuk menurunkan gairah selama satu hingga tiga bulan saja. Oleh karenanya, pemberian suntik obatnya harus dilakukan berulang kali sesuai dengan jangka waktu hukumannya. Dan alasan 
terakhir, hukuman kebiri tidak didukung oleh dokter di Indonesia. Hal ini terlihat dari penyataan Ketua Umum IDI, Ilham Oetama Marsis, bahwa ia meminta pemerintah tidak melibatkan dokter sebagai eksekutor dalam pelaksanaan hukuman kebiri.Ilham berargumen bahwa pengebirian itu akan bertentangan dengan fatwa Majelis Kehormatan dan Kode Etik Kedokteran (MKEK) Nomor 1 tahun 2016 tentang Kebiri Kimia, Sumpah Dokter, Serta Kode Etik Kedokteran. Selain itu, Ketua MKEK, Prijo Sidipratomo mengatakan bahwa dokter yang akan megeksekusi kebiri kimia akan dikeluarkan dari profesi dokter.Apabila suntikan obat kebiri kimia tidak diberikan oleh ahlinya, maka tentunya bisa berbahaya bagi kesehatan bahkan nyawa dari pelaku kekerasan seksual terhadap anak. ${ }^{8}$

\section{Kesimpulan}

Berdasarkan penelitian Perspektif Mahasiswa Fakultas Psikologi Angkatan 2015 Universitas Yarsi Jakarta Pusat Terhadap Aplikasi Chemical Castration (Kebiri) Bagi Pelaku Kekerasan Seksual Anak di Indonesia dan Tinjauannya Menurut Islam dapat ditarik kesimpulan sebagai berikut:

1. Berdasarkan penelitian ini, perspektif mahasiswa fakultas psikologi angkatan 2015 universitas yarsi jakarta pusat tidak setuju terhadap aplikasi chemical castration (kebiri) bagi pelaku kekerasan seksual anak di indonesia

2. Pada penelitian ini didapatkan bahwa perspektif mahasiswa fakultas psikologi angkatan 2015 universitas yarsi jakarta pusat terhadap aplikasi chemical castration (kebiri) bagi pelaku kekerasan seksual anak di indonesia tidak setuju sebanyak 18 responden dengan persentase $56,3 \%$ dan setuju sebanyak 14 responden dengan persentase $43,7 \%$.

\section{Saran}

Dari kesimpulan tersebut, terdapat saran yang dikemukakan oleh penulis sebagai berikut:

1. Kepada masyarakat diharapkan untuk selalu meningkatkan keilmuan dan pengetahuan agama agar dapat mempertimbangkan setiap peraturan yang akan diberlakukan di Indonesia

2. Adanya kerjasama berbagai pihak seperti pemerintah, kepolisian, dokter dan masyarakat dalam menangani kasus kekerasan seksual

3. Bagi peneliti selanjutnya, apabila memiliki kecukupan dana dan waktu dalam melakukan penelitian dengan variabel sama diharapkan penelitian ini dapat diteliti lagi dengan tempat penelitian yang luas dan jumlah sampel 
yang lebih banyak serta menggunakan metode penelitian yang berbeda atau dengan metode penelitian kualitatif.

\section{Daftar pustaka}

1. Humaira D, Rohmah N, Rifanda N, et al, 2015. Kekerasan Seksual Pada Anak: Telaah Relasi Pelaku Korban Dan Kerentanan Pada Anak. Jurnal Psikoislamika. 2, 5-10

2. Anonim, 2015 https://www. rappler.com/indonesa/110227-prokontra-hukuman-kebiri diakses 24 sep 2017 jam 21.20 di publis 22 oktober 2015

3. Anonim (2016). http://www.depkes. go.id/article/view/16051100002/menkes -pertimbangkan-efek-sampinghukuman-kebiri.html diakses pada 19 maret 2017 jam 13:02

4. Lee, J.Y., Cho, K.S., 2013. Chemical Castration for Sexual Offenders: Physician's Views. J Korean Med Sci. $28,171-172$

5. Vaillancourt S, 2012. Chemical Castration: How A Medical Therapy Becamepunishment And The Bioethical Imperative To Return To A Rehabilitative Model For Sex Offenders. Winston-Salem, North Carolina

6. Yesmil Anwar dan Adang, 2008. Pembaharuan Hukum Pidana,Jakarta: Grasindo. Hal 36
7. Sitepu NurPribudiarta, 2015, Pemberatan Hukuman bagi Pelaku Kejahatan Seksual terhadan Anak, Makalah Pada Diskusi Hukum Pidana, Sanksi Kebiri: Rasional Atau Emosional, Depok

8. Afifah,M.R 2016 Pengaturan Hukuman Kebiri Bagi Pemerkosa Anak,Surabaya. 